\title{
Proposing an Integrated Model on Knowledge Management for Organizational Excellence
}

\author{
*1Seyed Hassan. Tayyar \\ 2Saeed Kazemi
}

\section{Pedram Mireftekhari}

\author{
${ }^{1}$ Master of Science in Industrial Engineering; * Email: h.tayar@yahoo.com \\ ${ }^{2}$ Master of Science in Mechanical Engineering \\ ${ }^{3}$ Bachelor of Science in Industrial Engineering
}

Doi:10.5901/mjss.2016.v7n4s2p90

\begin{abstract}
During recent years, modern organizations, especially Iranian ones, governmental or private, have concluded that their knowledge management, resulted from human capitals, is a precious resource whom not being paid attention to and has more and more value than material resources. In development countries and leader companies, there are significant sensibilities over organizational knowledge and it is tried to properly maintain and utilize this resource. Different models have proposed for managing this intangible resource, which each one has its own advantages and disadvantages. This paper, analyzing remarkable executive models on Knowledge Management (KM) in internal (Iranian) organizations, which have invested in knowledge management processes and projects, tries to identify common and effective criteria and subjects of the area and select a proper model in accordance with internal organizational culture. Then it tries to select a proper integrated model applying suitable changes based on improvement of its performance and its integrating with related clauses of Knowledge management in European Foundation of Quality Management (EFQM), in order to co-directing knowledge plan with improvement strategies and organizational processes. Of considered criteria for proposing model, it can be referred to organizational values and cultures as well as its accordance with company's purposes and strategy, which are considered in variability and model development regarding the activities of each company.
\end{abstract}

Keywords: Knowledge, Knowledge Management, Strategy, Organizational Excellence

\section{Introduction}

Today, the main competitive advantages of organizations are the ability to manage knowledge and skills inside it. The most significant capital of all productive and service organizations, during the present era, is the competence and creativity of their human assets. Knowledge management have changed into an important and applicable issue in organization, and leader organization require to manage their organization knowledge to achieve their organizational goals. According to concepts in knowledge and management area, knowledge management can be simply considered as a set of activities of establishing, storing, sharing and applying knowledge. But it is better to considered it as a dynamic process in an executive environment. According to this, such a definition can be resulted: knowledge management is the process of creating knowledge from knowledge resources for organizations. The process of value creation is usually includes the categorizing and dividing the knowledge of employees, customers, and business partners, and making available of this resource for the employees, departments, and even other partners which are considered as best practices.

In a comprehensive and systematic definition by Texas University, knowledge management is the systematic process of exploring, selecting, organizing, summarizing, and proposing information so that it improves individual cognition in their area of interest. Knowledge management helps organization to achieve knowledge and insights from their experiments and concentrates its activities on achieving, storing and using knowledge to utilize this knowledge in problem solving, dynamic education, strategic planning, and decision making. Knowledge management not only prevents mental and brain deterioration, but also it increases constantly this asset (Alipour, 2009).

\section{Analyzed Models in Internal Organizations}

Regarding limitations and analyzing different knowledge management models and organization efficiency, this paper is 
just introducing models which are more related to the systematic concept of the knowledge management, are of more accepted models in the scientific community of this area, and possess more suitable executive and value approach considering being in accordance with and implementing in Iranian organizations. These models, in the knowledge area, include Nonaka \& Takeuchi, Probst et al, Heisig, and Mark W. McElroy, and in organizational efficiency, include European Foundation of Quality Management (EFQM) model, which are briefly discussed here.

\subsection{Nonaka \& Takeuchi model}

According to this model, the process of creating knowledge management is based on a principal framework consisted of two aspects: epistemological and ontological aspect. Its epistemological aspect indicates that just individuals create knowledge; its ontological aspect relates to the interaction between explicit knowledge and tacit knowledge. This two creates a basis for defining four process of knowledge: Socialization, Externalization, Internalization, and Combination. Following figure indicates briefly these concepts: (Abbasi, 2007)

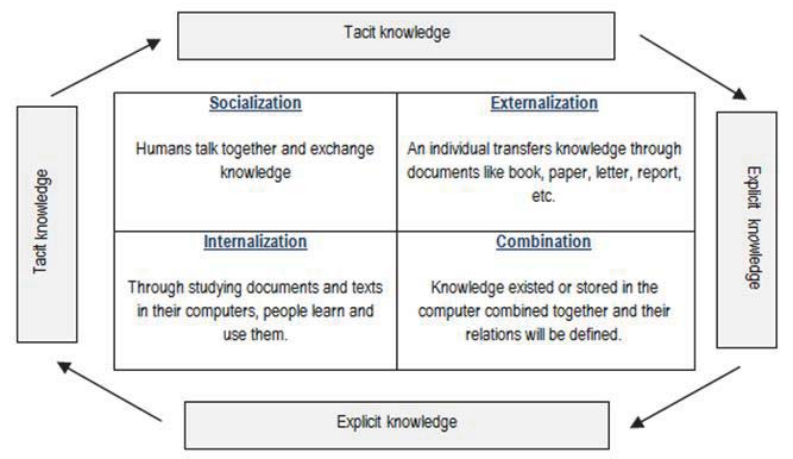

Figure 1. Nonaka \& Takeuchi model

\subsection{Probst et al and Heisig model}

Just like the previous model, these two models consider knowledge management as a dynamic circle which is constantly changing. Probst et al model includes of 8 elements located in two circles (internal and external circle). Internal circle is a combination of: identification, acquisition, development, sharing/distribution, utilization, and retention of knowledge.

Figure 2 provides Probst et al model. There are two other process in the external circle: knowledge goals and assessment which helps to the directing of the all knowledge management circle. These two process indicates the most differences between Probst et al and Heisig models. Heisig model possesses elements similar to internal circle of Probst et al model but it has four components: Creation, Storing, distribution and utilization.

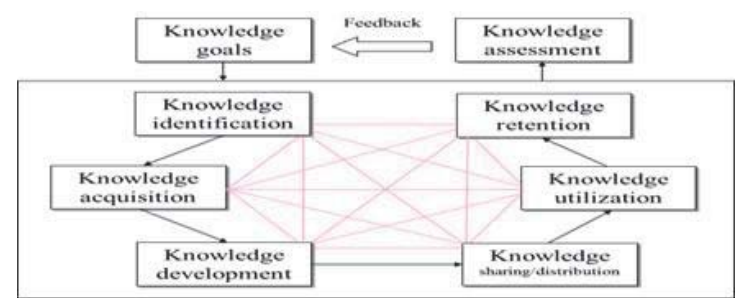

Figure 2. Probst et al model

\subsection{Mark W. McElroy model}

Mark W. McElroy defined a framework for the knowledge management, which is known as The Knowledge life cycle. This 
model is significant, since, in addition to the Nonaka \& Takeuchi model, it considered knowledge available after its creation and it is possible to its retrieval and also has the ability to compilation and distribution. This model divide the process of knowledge creating into two main processes:

- Knowledge Creation is a process in which a new knowledge is created. This knowledge is performed through separate group training, demanding knowledge, obtaining information, demanding developed knowledge, evaluating demanding knowledge. This process can be equal to organizational learning.

- Knowledge Integration is performed through activities result in knowledge distribution and division, which is included of propagation, search, education, distribution of knowledge and other social activities providing communication.

This model has two new concepts of Demand side and supply side (Adriana et al, 2003).

\section{European Foundation of Quality Management (EFQM) Model}

This is a non-prescribed framework confirms numerous different ways for achieving Sustainable Excellence. There is a set of basic concepts in support of this non-prescribed approach which is consisted of 9 criteria. These criteria are the core of the model and the basis for organization evaluation. Basic concepts indicate goals to which a leader organization shall achieve. The forth criteria are "Partnerships and resources" which is defined as: Excellent organizations, partnerships and external trade cooperation, suppliers manage their internal resources in order to support the strategy and effective performance of their processes. These organizations, during the planning and managing companies and resources, create balance between present and future demands of the organization, and between the society and the environment (Najmi \& Hoseini, 2003).

Given that each clauses of the model has a certain number of sub-criteria, the fourth criteria has also 5 sub-criteria:

4a: External trade cooperation is managed.

4b: financial resources are managed.

4c: Building, equipment, and material are managed.

$4 \mathrm{~d}$ : Technology is managed.

4e: Information and knowledge are managed.

As it is indicated in the sub-criteria of $4 \mathrm{e}, \mathrm{EFQM}$ model has considered information and knowledge as organization resources and reminds this requirement that "Information and knowledge shall be managed". The model provides points for each criteria, about 4 e criteria is as following:

- Creating and developing a strategy for information and knowledge management so that it protects organization strategy.

- Identifying information and knowledge requirements of the organization.

- Collecting, structuring and managing information and knowledge in support of strategy.

- Creating a desired availability for internal and external users to the related information and knowledge.

- Utilizing information technology in support of within organization relationships and information management.

- Ensuring and improving reliability, integrity, and information security.

- Training, developing and effective protecting knowledge.

- Generating creative thinking in the organization through related information and knowledge resources (Gervase, 2010).

\section{An Integrated Model for Performing Knowledge Management}

This model is an integrated model which is derived from models of Probst et al and public cycle of knowledge management, shown in the following picture, and also derived from some practices for $4 \mathrm{e}$ clause of Iranian and foreign declaration of organizational excellence of EFQM.

The model which is designed for analyzing organizational culture and their inside knowledge management models to improve circulation and knowledge management of knowledge-based organizations and companies, tries to provide some executive practices for 4 e clause in organizational excellence awards. Seven paragraphs of this model is defined so that organizations, through executing it, are able to response to all needs of EFQM award and are able to manage knowledge and their organizational information interestedly. 


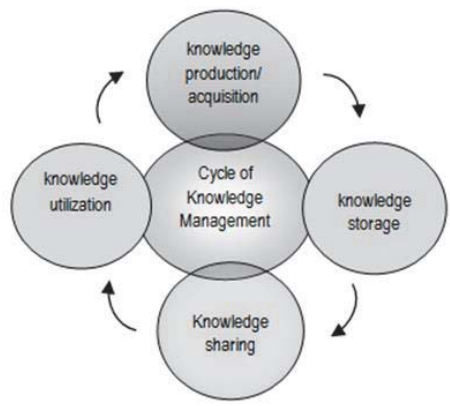

Figure 3. Public cycle of knowledge management

The model is designed as a reservoir model in which "information technology" is used for acquisition, organizing, storing and distributing objective knowledge of the organization. In reservoir models, knowledge is considered as an object which can be collected, stored and shared (Mohammadi, 2000).

As it is observed in the following figure, the cycle of the model is drawn which begins from identifying goals and strategy and through passing different processes ends into the same point. In the following, all model elements have been explained and identified.

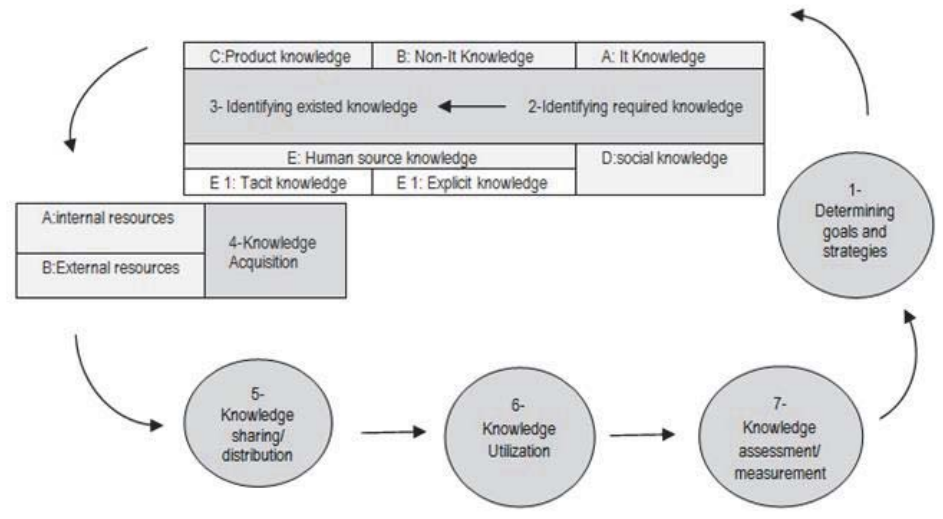

Figure 4. Knowledge management cycle of the integrated model

\section{Executive Model of Knowledge Management in Organizational Excellence}

1) Determining goals and strategies: knowledge-based organizations execute their mission and perspective through codifying a certain strategy, and long-term strategies, plans, and processes are codified and extended in organizations in such a way to be able to implement strategies.

- Organizations, considering certain features and utilizing following designed tables, can select their considered strategy and use it for achieving their knowledge goals. Managers and leaders of the organization can select their own knowledge management strategy through answering to the following questions: 
Table 1. Strategy Identification

\begin{tabular}{|l|l|l|}
\hline Questions & Coding Strategy & Personalization Strategy \\
\hline $\begin{array}{l}\text { Do you provide } \\
\text { standardized products or } \\
\text { ordered products? }\end{array}$ & $\begin{array}{l}\text { Products we sell don't create so many changes in all } \\
\text { products. In another words, our products are similar to } \\
\text { each other. }\end{array}$ & $\begin{array}{l}\text { We provide products and services on the } \\
\text { orders of the customers, and move toward } \\
\text { meeting exclusive needs and desires of a } \\
\text { number of certain customers. }\end{array}$ \\
\hline $\begin{array}{l}\text { Do your employees rely } \\
\text { on implicit knowledge or } \\
\text { Explicit knowledge? }\end{array}$ & Our employees prefer mostly to use explicit knowledge. & $\begin{array}{l}\text { Our employees prefer mostly to use } \\
\text { implicit knowledge. }\end{array}$ \\
\hline $\begin{array}{l}\text { Do you produce a } \\
\text { common and fix product } \\
\text { or a new product? }\end{array}$ & $\begin{array}{l}\text { We have reused more than one model. The process we } \\
\text { apply for designing and selling such products includes } \\
\text { practices, which are well understood and knowledge } \\
\text { which has the capability to being encoded. }\end{array}$ & $\begin{array}{l}\text { We are seeking for innovations and it is } \\
\text { required for the employees to exchange } \\
\text { their information. }\end{array}$ \\
\hline
\end{tabular}

2) Identifying Required knowledge: Organizations, regarding their own strategic plans and goals, specify knowledge requirements, determine the sources of providing each and introduce the way of achieving each.

- Knowledge identification is process in which external required knowledge for analyzing and describing organization Indigenous Knowledge is defined.

- Organization uses the following tools in order to identify its own knowledge: Specialty papers, Specialist Manual, notes and minutes, technical reports, and E-mails.

3) Identifying existed knowledge: In this stage, organization, through collecting information, informs its existed knowledge management and can use following ways to identify this existed knowledge:

- Identifying the employees skill

- Knowledge plans

In each of the above issues, identifying required knowledge and identifying existed knowledge, by knowledge and knowledge capital, it means a classification shown in the figure and the organization is required to analyze knowledge in the following issues and on the base of organizational goals.

A: IT knowledge: Applied Systems, Internet/Intranet, e-mail, shared system, virtual meetings and video conferences.

B: non-IT knowledge: Brochures, manuals, instructions, bulletin boards, prints, and library

C: Product knowledge: including knowledge for producing with the best and most economical production method. This kind of knowledge is structured and within the organization.

D: Social knowledge: is an image of an organization or complex shaped in the minds. For example; awareness of services provided in insurance companies or banks.

E: Human knowledge (Explicit or implicit): experiments, competences, creative thinking, and know-how knowledge processes.

4) Knowledge acquisition: Organization, regarding required and existed knowledge, acquires knowledge, and it has two resources for this:

4a: Internal resources: for acquiring knowledge based on internal resources, it can just rely on the hidden talents of its own employees.

4b: External resources: the organization can use knowledge of other companies' employees, knowledge of other companies, knowledge of beneficiaries, and knowledge production.

Table 2 explains the components of these resources.

Table 2. Sources of knowledge acquisition

\begin{tabular}{|l|l|}
\hline Knowledge of other companies' employees & $\begin{array}{l}\text { Employment on the base of required competency, limited contracts, General and } \\
\text { specialized consultants }\end{array}$ \\
\hline Knowledge of other companies & Strategic links (Collaboration), benchmarking, takeover. \\
\hline Knowledge of beneficiaries & Costumer recognition ${ }^{1}$, beliefs and ideas of the customer, using from customers ${ }^{2}$, \\
\hline
\end{tabular}

\footnotetext{
1 Through information obtained from market research

${ }^{2}$ Holding workshops
} 


\begin{tabular}{|c|c|}
\hline & $\begin{array}{l}\text { involving in the activities of the customer, pilot Projects }{ }^{3} \text {, understanding the } \\
\text { customer }^{4}\end{array}$ \\
\hline Knowledge production & $\begin{array}{l}\text { Registered knowledge, obtaining intellectual property }{ }^{5} \text {, legal duplication }{ }^{6} \text {, Reverse } \\
\text { Engineering. }\end{array}$ \\
\hline
\end{tabular}

5) Knowledge sharing and distribution: the organization is required to provide desirably the acquired knowledge to the addressees. Knowledge-based organization share their knowledge in systematic and non-systematic ways:

- Systematic way: including mechanical, electronic and personal transferring of information, and knowledge is consisted of reports, education, briefings and tours.

- Non-systematic way: including rotation of jobs and informal networks.

6) Use of knowledge: if all earlier stages has gone well, this stage is also performed by the employees and with the help of human resource management. The organization uses attracted knowledge in all stages and can apply it as a good for sell.

7) Knowledge assessment and measurement: the organization, with the approach to measuring the value of knowledge within the organization, shall assess and measure its own knowledge at certain times to show whether it achieve its goals. It shall also evaluate its processes. The organization is required to improve its processes regarding performed evaluations.

\section{Conclusion}

Considering the concepts of knowledge management and related concepts to the efficiency improvement and organizational excellence, it can be inferred that mentioned issues have a close relationship to each other, and management improvement in knowledge cycle may be results in effective use of human and knowledge management sources. Creating and executing a suitable management model in this regard can improve executive processes of the organizations and consequently can improve efficiency.

This paper, through analyzing new executive models of knowledge management in internal leader organizations and inspiring from collecting processes and knowledge documentations within them, refers to the effective executive model and, through combining it with knowledge related paragraph in EFQM model and applying necessary changes, tries to provide a suitable model for performing in internal organizations.

This proposed model, regarding the activities of each organizations and its dimensions, and considering the existed knowledge and the expected knowledge, can be extended and improved, and it can be possible to design strategy and knowledge plan of the organization for achieving considered goals, through using mentioned table of strategy identification.

\section{References}

Alipour, Vahideh. 2009, Knowledge Management: Definitions and Concepts. Center of Research and Media Studies of Hamshahri (newspaper).

Abbasi, Zohreh. 2007. A Review on Models for Implementing Knowledge Management in Organizations. National Conference of Knowledge Management.

Adriana Maria ORTIZ LAVERDE, Alvaro Fdez, BARAGAÑO and Jose Maria SARRIEGUI DOMINGUEZ, 2003, "Knowledge Processes: On Overview of the Principal Models," 3rd European Knowledge Management Summer School, San Sebastian, Spain.

Najmi, Manouchehr. Hoseini, Sirus. EFQM Excellence Model from Idea to Action (based on edition on 2003). Publication Institute for Productivity and Human Resources.

Gervase R. Bushe, 2010, "When People Come and Go", The Wall Street Journal.

Mohammadi, Mohammad. 2000. What is your Strategy for Knowledge Management? Journal of Tadbir, No.107.

\footnotetext{
3 Through publishing of Beta version

${ }_{4}$ Through terminology of the customer language

5 Through obtaining research results

6 Visiting of exhibitions
} 